\title{
Prediction of the Emissivity Curve at High Temperatures of Low Carbon Steel
}

\author{
Vinicius Santos de Deus ${ }^{1,2}$, José Adilson de Castro $^{3} \&$ Sandro Rosa Rosa Corrêa $^{4}$ \\ ${ }^{1}$ Gerência Geral de Folhas Metálicas - GGFM, Companhia Siderúrgica Nacional - CSN, Volta Redonda, RJ, \\ Brazil \\ ${ }^{2}$ Programa de Pós-Graduação em Engenharia Metalúrgica - PPGEM, Universidade Federal Fluminense - UFF, \\ Volta Redonda, RJ, Brazil \\ ${ }^{3}$ Programa de Pós-Graduação em Engenharia Metalúrgica - PPGEM, Universidade Federal Fluminense - UFF, \\ Volta Redonda, RJ, Brazil \\ ${ }^{4}$ Gerência Geral de Pesquisa e Desenvolvimento - GGPD, Companhia Siderúrgica Nacional - CSN, Volta \\ Redonda, RJ, Brazil \\ Corresponding author: Jose Adilson de Castro, Programa de Pós-Graduação em Engenharia Metalúrgica - PPGEM, \\ Universidade Federal Fluminense - UFF, Volta Redonda, RJ, Brazil. Email: joseadilsoncastro@id.uff.br
}

Received: January 16, 2020

Accepted: March 26, 2020

Online Published: April 30, 2020

doi:10.5539/jmsr.v9n2p59

URL: https://doi.org/10.5539/jmsr.v9n2p59

\begin{abstract}
The thermography is an attractive technique to record the real-time temperature during the continuous welding processes. The temperature distribution during the weld zone is essential for understanding and evaluating the metallurgical properties of the joints. The knowledge of the material emissivity curve is necessary for the precise acquisition of thermography data. This emissivity value is usually assumed constant in the thermography software data acquisition, resulting in inaccurate thermographic data. The surface emissivity usually depends on the temperature. Thus, the values obtained in the literature may not be valid for materials of interest under the process's conditions. Especially in the case of the low carbon steels, the emissivity data available are scarce and frequently obtained at low temperatures (below $200^{\circ} \mathrm{C}$ ). Therefore, we proposed a methodological procedure to measure the effective surface emissivity, which considers the effect of temperatures and surface conditions. This research was focused on the development of an experimental methodology for determining the emissivity curve, using as the sample, a low carbon steel $(0.07 \% \mathrm{C})$ with $0.21 \mathrm{~mm}$ thickness obtained from the productive stock of a continuous annealing line in the steel plant of the Companhia Siderúrgica Nacional (CSN). The normal sample emissivity was evaluated in the temperature range from $100^{\circ} \mathrm{C}$ to $800^{\circ} \mathrm{C}$. It was proposed a model based on a sigmoid function to represent the effective emissivity during temperature rise. The sigmoid model parameters were obtained by a fitting procedure using temperature measurements obtained by thermocouples. The results showed an effective emissivity variation as a function of temperature, where emissivity values raged in the interval of 0.09 to 0.83 . Thus, the useful emissivity curve was used to correct the thermography data obtained in electrical resistance seam welding (RSEW) with three levels of heats inputs. The correlation for the emissivity curve incorporated in the thermography software was applied to the thermal profiles of the welds analyzed from $441^{\circ} \mathrm{C}$ to $713^{\circ} \mathrm{C}$. These values are consistent with the welding process used. The developed methodology can be applied, in a similar way, in the correction of profiles in other types of welding processes.
\end{abstract}

Keywords: thermography, emissivity curve, methodology, welding, low carbon steel

\section{Introduction}

The carbon steel has an outstanding application in the engineering branches, mainly due to its low production cost combined with the material properties. Low carbon steels include both carbon sheets of steel with up to $0.15 \%$ carbon, so-called low carbon steels, such as those with $0.15 \%$ to $0.30 \%$ carbon, the so-called mild steels (Kou, 2003). Among the different types of steels, those with low carbon content are produced in larger quantities. Common low carbon steel alloys have low hardness and low strength characteristics, but good ductility and toughness. Its production is the cheapest of all types of steel. As typical applications, it can be mentioned in 
automobiles, beams, gutters, pipes, general packaging, etc. In general, they have a flow limit of $275 \mathrm{MPa}$, tensile strength limits between $415 \mathrm{MPa}$ and $550 \mathrm{MPa}$ and $25 \%$ of elongation.

Regarding the industries involving metals and their alloys, the welding process is the most used process applied for the union of these materials. Usually, the material region adjacent to the weld may also exhibit changes in microstructure and mechanical properties due to temperature variation during the process. This region is called the heat-affected zone (HAZ). HAZ is the portion of the material that has not melted, but the welding heat alters the microstructure and mechanical properties. It is well established in the literature, Bhadeshia and Honeycombe (Bhadeshia \& Honeycombe 2006), Demarque et al. (Demarque et al., 2017; Demarque et al., 2018) and Xavier et al. (Xavier et al., 2011; Xavier et al., 2016), that the thermal cycle at any position within the HAZ is influenced by the welding energy, which directly affects the maximum temperature and the cooling time (Silva et al., 2019).

About the welding processes inspection in real-time, the use of thermography technique has been an advantage associated with its non-destructive and non-contact characteristics, thus presenting a strong attractiveness in its application in the analysis of welds in industrial automated processes (Chen \& Feng, 2015; Broberg et al.,2015).

Thermography is defined as the technique of area temperature mapping, where it is possible to identify different temperatures regions, making use of electromagnetic radiation within the infrared spectrum, which is naturally emitted by a body with intensity proportional to its temperature. The electromagnetic energy radiated by a body depends strongly on its surface emissivity, which can be defined as a measure of the radiation efficiency or the absorption efficiency of a body surface (the capacity of a body to absorb energy is proportional to that of emitting energy). Thus, the higher the emissivity value, the greater the body's ability to emit energy (Palacios, 2010; Brioschi, 2011). The blackbody is defined within Physics as an ideal body capable of absorbing all incident radiation and, according to the principle of energy conservation, is considered a perfect transmitter in all directions throughout the spectral domain, depending only on the temperature. The material emissivity is defined as the ratio of its luminance to the blackbody luminance subjected to the same temperature so that the emissivity is expressed in a dimensionless form in values between 0 and 1 (Valiorgue et al., 2013).

Depending on the application, there is the possibility of imprecision of the thermography method due to the emissivity variation of the analyzed surfaces. Representative values for emissivity obtained in the literature may not be valid for materials of interest under process conditions. The surface emissivity usually depends on the temperature, wavelength, surface geometry, roughness, the direction of observation, and there are always changes due to oxidation, fusion, protective coverings, and even superficial contaminations. Also, the emissivity can be influenced by the method of material manufacturing, thermal cycles, and possible chemical reaction with the environment fluids. Among the variables correlated with emissivity interference, the temperature plays a significant role with significant effects on the data analysis (Maziar et al., 2011).

The usual emissivity values of some engineering materials, according to the origin or their use, can be found through tables of the properties of the materials furnished by the manufacturers, usually at room temperatures. However, for several important materials used in a variety of thermal systems are adopted estimated values due to the lack of experimental results for a wide range of temperatures (Perin, 2009).

Most of the research, which used thermography in the welding processes evaluation, has been based on constant values of emissivity, due to the lack of knowledge of its variations in the materials during welding. These are the case of results reported by Boillot et al. (Boillot et al.,1985), Chen and Feng (Chen \& Feng, 2015) and Woo et al. (Woo et al., 2009), which evaluated thermal signatures in welding processes using thermography method based on constant values of emissivity. Thus, most of the available data did not consider the effects of the temperature changes on the emissivity properties.

The emissivity property, when considered in the normal direction to the surface, is commonly referred to as normal emissivity. The emissivity is called hemispheric when it considers the average radiation in all directions from the evaluated point (Perin, 2009). The values corresponding to the normal and hemispherical emissivity in the same thermal system, in general, although close, are not identical but present general correlation. In ferrous materials, the ratio of hemispherical emissivity to normal emissivity can range from 1.3 to approximately 1 , according to the normal emissivity value (Darmstadt et al., 2006). Figure 1 shows the relation between the hemispheric and normal emissivities values in steels. Thus this relationship is used to obtain the conversion of these properties. 


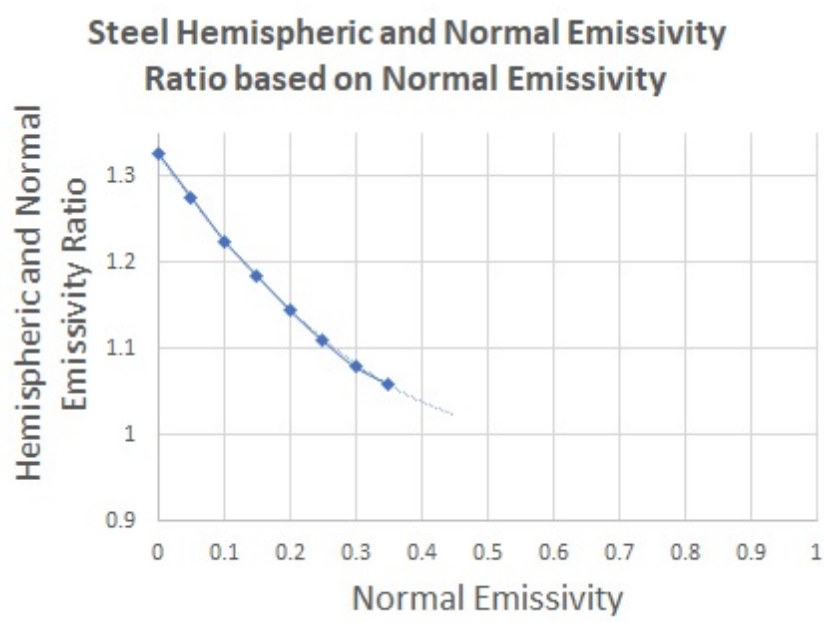

Figure 1. The relation between the hemispheric and normal steels emissivity. Figure constructed with the data from Darmstadt et al. (Darmstadt et al., 2006).

Although methods for measuring emissivity have already been proposed and applied for different materials, there is still no standard procedure or methodology universally accepted with suitable accuracy. It is recognized that the measurement of emissivity is difficult in practice due to the influence of variables such as material reflectivity, instrument calibration, surface homogeneity and interference from the environment (Novo et al. 2014; Paloposki \& Liedquist, 2005; Richmond \& Harrison, 1962; Deus, 2019, Deus et al., 2020).

The Stefan-Boltzmann equation has been used to address the emissivity of steel with variable compositions, as reported by Paloposki \& Liedquist (2005) and Richmond \& Harrison (1962). Reported data using similar experimental procedures considered the emissivity properties and the effects of temperature on the stainless-steel samples at a maximum temperature of $550^{\circ} \mathrm{C}$. In their research, the emissivity variation was determined by comparing the behavior of the material with that of the simulated blackbody through numerical integrations based on the Planck`s Law (Valiorgue et al., 2013).

Measured data for low carbon steel is scarce, although the recognized importance for several industrial applications. Accurate data extrapolations and measurements at the range from the environment to high temperatures are not available ate the literature for the low carbon steel considered in this study. Therefore, we newly present a method to evaluate the emissivity of the low carbon steel in a broader range of temperatures $\left(25-800^{\circ} \mathrm{C}\right)$ and successfully used these data to correct the real-time measurement of the temperature profile during the continuous welding process by using the thermographic technique.

In order to base subsequent thermographic evaluations on welds made throughout the steel production process, the present research focused on the development of a methodology for the normal emissivity curve experimental determination, using, as the sample, a low carbon steel $(0.07 \% \mathrm{C})$ with $0.21 \mathrm{~mm}$ thickness obtained from the productive stock of a continuous annealing line from the CSN steel plant (Deus, 2019; Deus et al., 2020). Subsequently, the results were compared with the data obtained through other methodologies developed from correlated researches. The results were used in the correction of the thermal profiles obtained with sample welding thermography, proving that the methodology can be applied, in a similar way, in the correction of thermal profiles during the evaluation of the other materials welding procedures in industrial processes.

\section{Materials and Methods}

\subsection{Material}

Samples of $0.21 \mathrm{~mm}$ thick steel plate were obtained from a selected coil within the productive stock of a continuous annealing process at the CSN steel plant in Brazil. The material is classified as low carbon steel, subjected to an $89 \%$ reduction in the previous cold rolling process. The chemical composition analysis is shown in Table 1. 
Table 1. Sample chemical composition analysis (optical spectroscopy method)

\begin{tabular}{ccccccccc}
\hline \multicolumn{10}{c}{ Sample Chemical Composition (\%) } \\
\hline $\mathrm{C}$ & $\mathrm{Mn}$ & $\mathrm{P}$ & $\mathrm{S}$ & $\mathrm{Si}$ & $\mathrm{Cu}$ & $\mathrm{Ni}$ & $\mathrm{Cr}$ & $\mathrm{Al}$ \\
0.074 & 0.333 & 0.013 & 0.010 & 0.003 & 0.009 & 0.007 & 0.010 & 0.027 \\
\hline
\end{tabular}

\subsection{Data acquisition and Emissivity Curve determination}

The following instruments and equipment were used in this experiment with the corresponding specifications:

- Thermocouple type $\mathrm{K}$ (Cromel/Alumel) $-270 / 1370^{\circ} \mathrm{C}$, used in the sample temperature measurement;

- Fluke data acquisition unit, model Hydra, used to read the sample thermocouple signal;

- Brasimet industrial furnace, type $\mathrm{K} 250 \mathrm{MP}, 7.6 \mathrm{KW}, 1300^{\circ} \mathrm{C}$, with GEFRAN temperature controller/programmer, model 3500 integrated with a type $\mathrm{K}$ thermocouple installed internally to the furnace;

- Thermal Camera - Flir T440 thermal imager, 240 x 320 pixels (76,800 pixels), 30 frames per second, temperature scales at $-20^{\circ} \mathrm{C} / 250^{\circ} \mathrm{C}, 0 / 650^{\circ} \mathrm{C}$ and $250^{\circ} \mathrm{C} / 1200^{\circ} \mathrm{C}$;

- Thermography software Flir Tools+.

Samples of $350 \times 350 \mathrm{~mm}$ of the material were cut, and the K-type thermocouple was soldered by fusion at the center and surface of this plate. The thermocouple was connected to the signal acquisition channel by the extension cable. The industrial furnace was maintained with its door open, and the sample was strategically placed in the opening of the industrial furnace with the aid of two steel weights. The details of the apparatus for measurements and the peripheral system can be visualized in Figure 2. It can be identified the furnace, the sample holder, thermocouple position and fixation, data acquisition system and connectors.

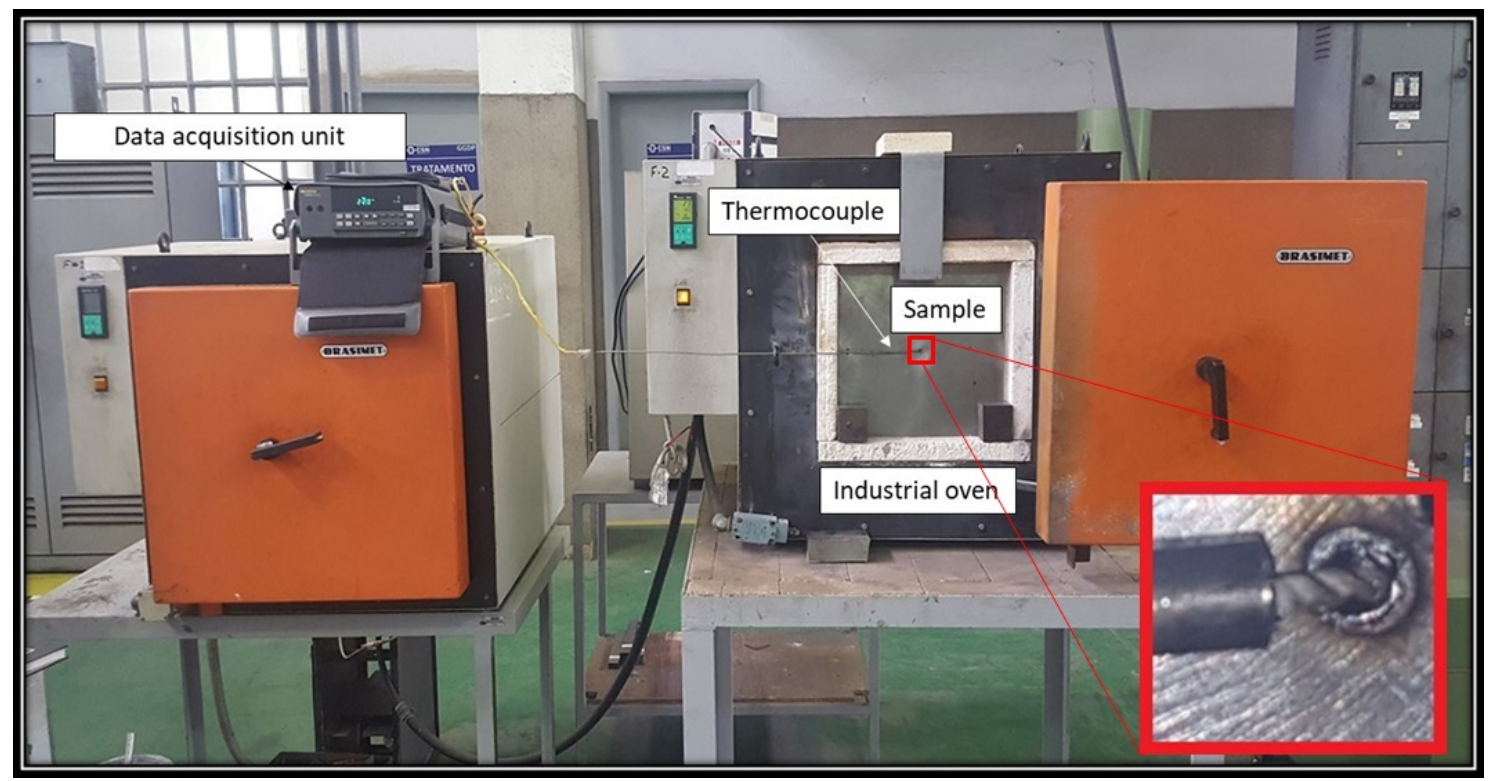

Figure 2. Experimental apparatus arrangement, equipment, instrumentation and data acquisition for the material emissivity measurements.

A procedure was designed to determine the temperature reflected in the test environment for higher thermographic camera accuracy. The thermal camera was set for an emissivity equal to 1 and a reading distance of $1 \mathrm{~m}$ (smaller distance parametrization allowed) and maintained for all measurements. A previously prepared surface (corrugated aluminum sheet) was subjected to a thermogram reading to simulate the maximum environment reflection and used as a reference for the system. Figure 3 illustrates this procedure. The image obtained during this initial reference measurement is shown. 


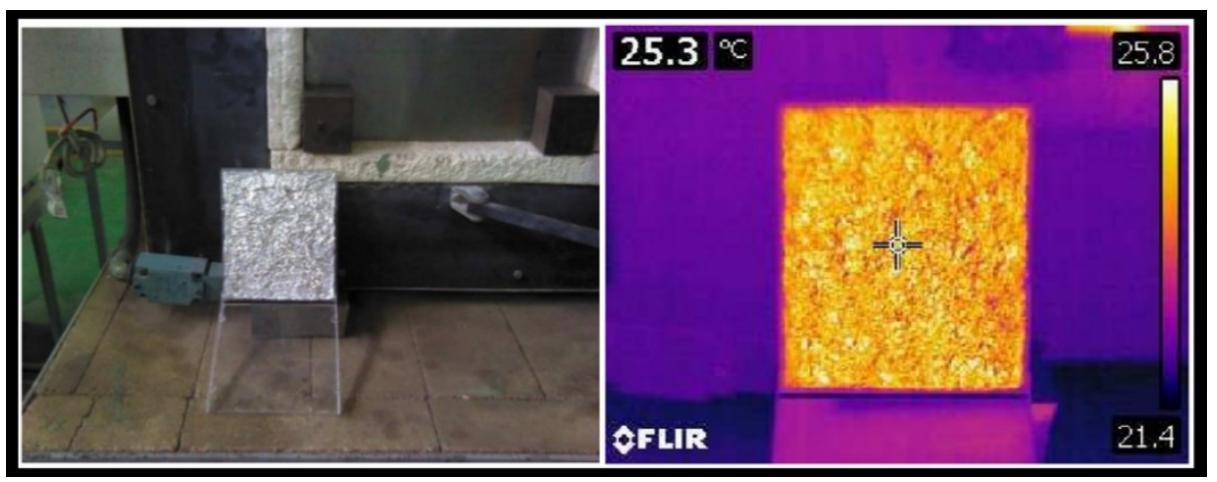

Figure 3. Prepared surface and thermographic camera image reference for the reflection temperature simulation.

The parameters set on the thermographic camera for the emissivity test were summarized:

- Reference emissivity: 0.95;

- Reflected temperature: $25^{\circ} \mathrm{C}$;

- Relative humidity: $50 \%$, obtained through weather measurements;

- Color palette: iron;

- Measuring distance: $2 \mathrm{~m}$;

- Temperature ranges (adjusted as the sample temperature increased): $-20^{\circ} \mathrm{C} / 250^{\circ} \mathrm{C}, 0 / 650^{\circ} \mathrm{C}$, and $250^{\circ} \mathrm{C} / 1200^{\circ} \mathrm{C}$.

The furnace was switched on with its temperature set up at $1300^{\circ} \mathrm{C}$, initiating the experiment. According to the sample temperature rise, specific variables were recorded at each $50^{\circ} \mathrm{C}$ read through the thermocouple placed in the sample surface. The initial reference temperature considered in the sample was $100^{\circ} \mathrm{C}$, and the final temperature was $800^{\circ} \mathrm{C}$. Higher sample temperatures were not possible to achieve due to the power of the furnace. The information is recorded for a specific time interval for internal furnace temperature, sample temperature and the thermogram captured at each $50{ }^{\circ} \mathrm{C}$ interval.

Based on the recorded values, the thermograms were simulated in the Flir Tools + software by adjusting the emissivity parameter to indicate the temperature value closest to that read through the sample thermocouple. By using this methodology, the test values were archived in a database and further used to the data analysis and determination of the material emissivity curve.

In the thermograms analysis, maximum, minimum, and average temperature values were considered within an area of 1771 monitored points resolution. In this way, the maximum, average, and minimum emissivity curves could be determined using the optimization technique. Figure 4 illustrates the area taken as reference in thermographic analyzes.

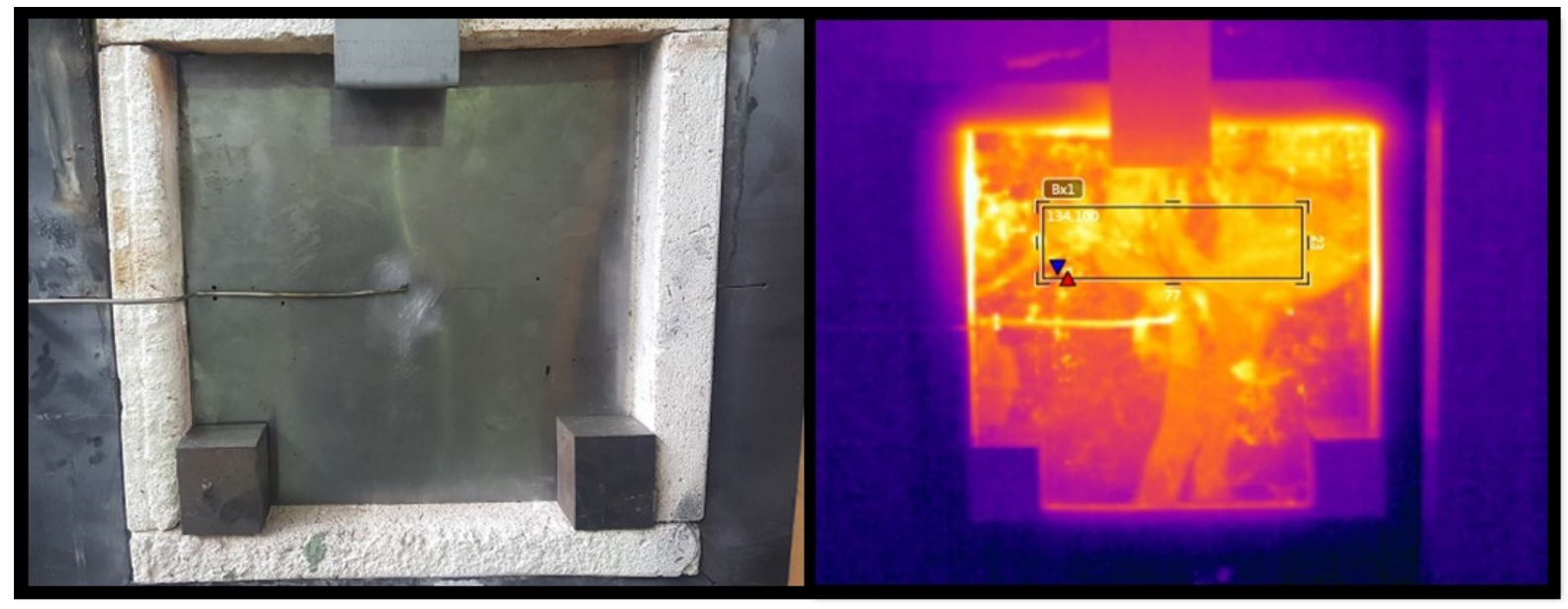

Figure 4. Reference area selection and the representative image for the thermographic analyzes. 


\subsection{Use of the emissivity curve to the thermographic data correction}

The welding thermal profiles were determined by using thermography performed on the sample welding tests. The thermography software was parameterized with constant emissivity $(\mathrm{e}=0.27)$ and the welds were carried out in an industrial welding machine by electric resistance by seam to join steel coils in the continuous annealing line at CSN company. Three heats inputs were imposed to verify the correspondent temperature variation along with the welding procedure. The welding parameters are shown in Table 2.

A methodology was developed, focusing on the general thermographic data correction using the emissivity curve, for the correlation between these two data sets. This methodology was organized in the following stages:

- Using as reference the temperature value the thermograms obtained with an independent fixed emissivity setting, determine the corresponding coordinate (emissivity $\mathrm{x}$ temperature) in the material emissivity curve;

- With the new emissivity value obtained by the emissivity $\mathrm{x}$ temperature curve, its value is updated in the Flir Tools + thermography software, and the new corrected temperature value is recorded;

- Repeat the previous two steps until convergence between the values of temperature with the corresponding emissivity value in both the thermography software and the material emissivity curve.

Table 2. Welding experimental data

\begin{tabular}{ccccccc}
\hline & \multicolumn{2}{c}{ Welding Variables } & \multicolumn{3}{c}{ Welding Parameters } & Heat Input \\
\hline \multirow{2}{*}{ Sample } & $\begin{array}{c}\text { Welding time } \\
(\mathrm{s})\end{array}$ & $\begin{array}{c}\text { Voltage rms } \\
(\mathrm{V})\end{array}$ & $\begin{array}{c}\text { Current rms } \\
(\mathrm{A})\end{array}$ & $\begin{array}{c}\text { Welding speed } \\
(\mathrm{mpm})\end{array}$ & $\begin{array}{c}\text { Welding } \\
\text { pressure }(\mathrm{bar})\end{array}$ & $\begin{array}{c}\text { Calculated heat } \\
\text { input }(\mathrm{J} / \mathrm{mm})\end{array}$ \\
\hline 1 & 4.76 & $0.104+/-0$ & $6242+/-132$ & $10.7+/-0$ & $2.8+/-0.1$ & $3.64+/-0.08$ \\
2 & 4.78 & $0.118+/-0$ & $7698+/-135$ & $10.7+/-0$ & $2.8+/-0.1$ & $5.09+/-0.09$ \\
3 & 4.73 & $0.131+/-0$ & $8687+/-139$ & $10.7+/-0$ & $2.8+/-0.1$ & $6.38+/-0.10$ \\
\hline
\end{tabular}

\section{Results and Discussion}

\subsection{Emissivity curve correction}

Table 3 presents the data obtained from the material emissivity experiments. These data demonstrated differences among the actual temperature obtained by the thermocouple and the thermography temperature with constant emissivity (0.95). These results indicate that the use of constant emissivity as a reference value for the acquisition of thermographic data is inaccurate to analyze and control processes in which the temperature variation is high.

Table 3. Emissivity data records as a function of temperature

\begin{tabular}{|c|c|c|c|c|c|c|}
\hline \multicolumn{4}{|c|}{ Thermographic camera } & \multicolumn{3}{|c|}{ Experiment } \\
\hline $\begin{array}{l}\text { Adjusted } \\
\text { scale }\left({ }^{\circ} \mathrm{C}\right)\end{array}$ & $\begin{array}{c}\text { Adjusted } \\
\text { parameters }\end{array}$ & $\begin{array}{c}\text { Thermogram } \\
\text { reference } \\
\text { number }\end{array}$ & $\begin{array}{c}\text { Sample mean } \\
\text { temperature } \\
\left({ }^{\circ} \mathrm{C}\right)\end{array}$ & $\begin{array}{l}\text { Absolute } \\
\text { time } \\
\text { (hh:mm) }\end{array}$ & $\begin{array}{c}\text { Furnace } \\
\text { temperature } \\
\left({ }^{\circ} \mathrm{C}\right)\end{array}$ & $\begin{array}{c}\text { Sample } \\
\text { thermocouple } \\
\text { temperature } \\
\left({ }^{\circ} \mathrm{C}\right)\end{array}$ \\
\hline \multirow[t]{5}{*}{$-20-120$} & & 1 & 33 & 00:00 & 156 & 100 \\
\hline & & 2 & 42 & 00:06 & 236 & 150 \\
\hline & & 3 & 52 & $00: 16$ & 339 & 210 \\
\hline & & 4 & 61 & $00: 21$ & 386 & 250 \\
\hline & & 5 & 71 & $00: 29$ & 460 & 302 \\
\hline \multirow{6}{*}{$0-650$} & $\mathrm{e}=0.95 ;$ reflected & 6 & 82 & $00: 35$ & 515 & 350 \\
\hline & temperature $=25^{\circ} \mathrm{C}$; & 7 & 115 & $00: 42$ & 572 & 405 \\
\hline & distance = $2 \mathrm{~m}$ & 8 & 277 & $00: 50$ & 620 & 454 \\
\hline & $\begin{array}{c}\text { relative } \\
\text { umiditv }=50 \% .\end{array}$ & 9 & 399 & $00: 58$ & 676 & 495 \\
\hline & umidity $=50 \%$ & 10 & 427 & $01: 13$ & 750 & 550 \\
\hline & color palette=Iron & 11 & 518 & 01:29 & 828 & 602 \\
\hline \multirow{4}{*}{$250-1200$} & & 12 & 576 & 01:38 & 870 & 645 \\
\hline & & 13 & 684 & $01: 56$ & 949 & 726 \\
\hline & & 14 & 724 & $02: 28$ & 1033 & 761 \\
\hline & & 15 & 763 & $02: 33$ & 1048 & 783 \\
\hline
\end{tabular}

Due to these variations in thermocouple and pixel techniques, continuous optimization of the emissivity curve was made, which best correlates these data set. The recorded thermograms were simulated in the software FLIR Tools + by adjusting the emissivity parameter to indicate the temperature value closest to that read by the thermocouple. The maximum, minimum and average temperature values within the 1771 monitored points resolution area were 
corrected and the corresponding maximum, minimum and average emissivity curves could be determined. Table 4 and Figure 5 summarizes the results. It can be verified the existence of a variation margin in the emissivity curve represented by the maximum and minimum emissivity curves, which may be attributed to the nonuniformity of oil residues distribution in the sample surface, usually inherent in the steelmaking process.

Table 4. Emissivity parameter software adjustments based on sample temperature

\begin{tabular}{|c|c|c|c|c|c|c|c|}
\hline $\begin{array}{c}\text { Thermogram } \\
\text { reference } \\
\text { number }\end{array}$ & $\begin{array}{c}\text { Sample } \\
\text { thermocouple } \\
\text { temperature }\left({ }^{\circ} \mathrm{C}\right)\end{array}$ & $\begin{array}{c}\text { Corrected } \\
\text { maximum } \\
\text { temperature } \\
\left({ }^{\circ} \mathrm{C}\right) \\
\end{array}$ & $\begin{array}{c}\text { Emissivity } \\
\text { corrected to } \\
\text { the maximum } \\
\text { temperature }\end{array}$ & $\begin{array}{l}\text { Corrected } \\
\text { minimum } \\
\text { temperature } \\
\left({ }^{\circ} \mathrm{C}\right) \\
\end{array}$ & $\begin{array}{c}\text { Emissivity } \\
\text { corrected to } \\
\text { the minimum } \\
\text { temperature }\end{array}$ & $\begin{array}{c}\text { Corrected } \\
\text { mean } \\
\text { temperature } \\
\left({ }^{\circ} \mathrm{C}\right) \\
\end{array}$ & $\begin{array}{c}\text { Emissivity } \\
\text { corrected to } \\
\text { the mean } \\
\text { temperature }\end{array}$ \\
\hline 1 & 100 & 100 & 0.31 & 98 & 0.05 & 100 & 0.09 \\
\hline 2 & 150 & 151 & 0.29 & 158 & 0.06 & 156 & 0.09 \\
\hline 3 & 210 & 211 & 0.26 & 202 & 0.06 & 206 & 0.09 \\
\hline 4 & 250 & 253 & 0.22 & 261 & 0.06 & 241 & 0.09 \\
\hline 5 & 302 & 306 & 0.28 & 307 & 0.07 & 299 & 0.09 \\
\hline 6 & 350 & 347 & 0.25 & 342 & 0.08 & 360 & 0.09 \\
\hline 7 & 405 & 403 & 0.28 & 408 & 0.10 & 408 & 0.14 \\
\hline 8 & 454 & 454 & 0.60 & 461 & 0.19 & 455 & 0.40 \\
\hline 9 & 495 & 497 & 0.84 & 493 & 0.51 & 496 & 0.69 \\
\hline 10 & 550 & 551 & 0.82 & 548 & 0.61 & 549 & 0.68 \\
\hline 11 & 602 & 602 & 0.80 & 601 & 0.67 & 603 & 0.73 \\
\hline 12 & 645 & 644 & 0.85 & 646 & 0.63 & 644 & 0.72 \\
\hline 13 & 726 & 728 & 0.88 & 727 & 0.60 & 726 & 0.81 \\
\hline 14 & 761 & 760 & 0.90 & 756 & 0.66 & 760 & 0.83 \\
\hline 15 & 783 & 785 & 0.90 & 787 & 0.66 & 785 & 0.83 \\
\hline
\end{tabular}

Similarly, Paloposki and Liedquist (Paloposki \& Liedquist, 2005) analyzed cold-rolled low carbon steel with a thickness of $1.5 \mathrm{~mm}$ at a temperature range of $150^{\circ} \mathrm{C}$ to $550^{\circ} \mathrm{C}$ and its hemispherical emissivity curve was converted into a normal emissivity curve using the conversion ratio represented in Figure 1. It was represented (as " $\mathrm{e}$ reference") in Figure 5, where it is possible to observe that the curve was in the same range of measured values of the present study. The results of Richmond and Harrison (Richmond \& Harrison, 1962) also showed a similar pattern and correlated with the results obtained in this work. In their research, the study was conducted to survey the hemispherical emissivity curve in polished stainless steels and stainless steels under oxidation conditions. Their results of emissivity are obtained at temperatures below $400^{\circ} \mathrm{C}$ for polished stainless steels and temperatures above $400^{\circ} \mathrm{C}$ for stainless steels submitted to oxidation. Their emissivity values are also consistent with the data obtained in the present work. However, they did not present data for emissivity varying with the temperature dynamically, which could not directly be compared with the actual data.

\section{Emissivity Curve}

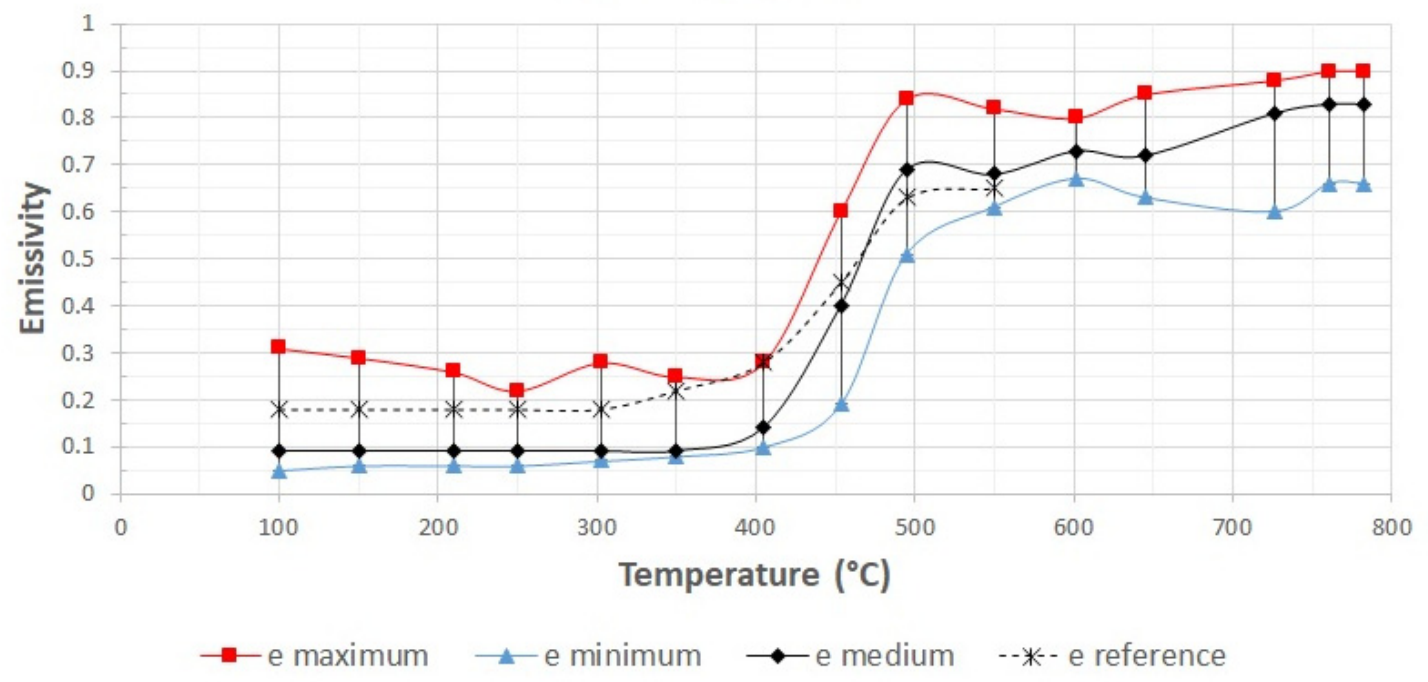

Figure 5. Determined material experimental effective emissivity curve 
Richmond and Harrison (Richmond \& Harrison, 1962) argued that the emissivity value is lower in polished surfaces and higher in oxidized surfaces, being dependent on its chemical composition, internal structure, and strongly affected by surface conditions [15]. In the present experiment, the sample darkening (burning of the oil cover and oxidation) was observed from the temperature close to $400^{\circ} \mathrm{C}$, which may justify the sharp increase in emissivity at this point.

\subsection{Correction of the emissivity curve using a model based on the sigmoid function}

To enable corrections in thermographic evaluations using the correct emissivity value, the sample means emissivity curve was taken as a reference, due to the higher representation of the sample characteristics.

To attain the convergence between the values of temperature and emissivity in the methodology of thermographic data correction by the emissivity curve, a sigmoid function was used from the mean emissivity curve aiming at an amortization of the noises present in the real curve. Equation 1 describes the sigmoid function, being " $\sigma, "$ the sigmoid function, "e," the Euler number, and "a" the function setting parameter (Deus, 2019).

$$
\sigma=\frac{1}{\left(1+e^{-a}\right)}
$$

The sigmoid function was adjusted by a $\Delta \mathrm{a}$ of 1 unit for a better correlation with the actual mean emissivity curve. With the adjustments, it was possible to obtain a determination coefficient $\left(\mathrm{R}^{2}\right)$ of 0.9861 , which proved to be an acceptable representation of the adjusted real emissivity curve. Table 5 shows the data used in the sigmoid function adjustments.

Figure 6 illustrates the graphical comparison between the actual mean emissivity curve and the sigmoid function. Error bars represent the edges of the emissivity represented by their maximum and minimum limits. It is verified that the sigmoid function presented an acceptable correlation with the actual emissivity curve within the limits of the error bars, evidencing its representativity of the sample real emissivity.

The sigmoidal function was applied to correct the thermographic data acquisition previously shown in Table 3. Figure 7 shows the comparison of the temperature measured for thermocouples and the average temperatures obtained with the thermographic camera. Figure 7(a) shows the measured values assuming constant emissivity and Figure 7 (b) presents the same comparison when the sigmoidal emissivity curve is used to obtain the average temperature using the thermographic camera.

Table 5. Sigmoid function from the real emissivity curve

\begin{tabular}{|c|c|c|c|c|c|}
\hline \multicolumn{2}{|c|}{ Emissivity curve } & \multicolumn{2}{|c|}{ Sigmoid } & \multirow{2}{*}{$\begin{array}{l}\text { Emissivity sigmoid } \\
\varepsilon=(\Delta \varepsilon \times \sigma)+\varepsilon_{\text {min }}\end{array}$} & \multirow{2}{*}{$\begin{array}{r}\begin{array}{r}\text { The determination } \\
\text { coefficient }\left(\mathrm{R}^{2}\right)\end{array} \\
\mathrm{R}^{2}=\frac{\sum_{i=1}^{n}\left(\hat{y}_{i}-\bar{y}\right)}{\sum_{i=1}^{n}\left(y_{i}-\bar{y}\right)}\end{array}$} \\
\hline $\begin{array}{c}\text { Temperature } \\
\left({ }^{\circ} \mathrm{C}\right)\end{array}$ & Emissivity & $\mathrm{a}$ & $\sigma=\frac{1}{\left(1+e^{-a}\right)}$ & & \\
\hline 100 & 0.09 & -7 & 0000911051 & 009 & \\
\hline 156 & 0.09 & -6 & 0.002472623 & 0.09 & \\
\hline 206 & 0.09 & -5 & 0.006692851 & 0.09 & \\
\hline 241 & 0.09 & -4 & 0.017986210 & 0.10 & \\
\hline 299 & 0.09 & -3 & 0.047425873 & 0.13 & \\
\hline 360 & 0.09 & -2 & 0.119202922 & 0.18 & \\
\hline 408 & 0.14 & -1 & 0.268941421 & 0.29 & \\
\hline 455 & 0.40 & 0 & 0.500000000 & 0.46 & 0.9861 \\
\hline 496 & 0.69 & 1 & 0.731058579 & 0.63 & \\
\hline 549 & 0.68 & 2 & 0.880797078 & 0.74 & \\
\hline 603 & 0.73 & 3 & 0.952574127 & 0.79 & \\
\hline 644 & 0.72 & 4 & 0.982013790 & 0.82 & \\
\hline 726 & 0.81 & 5 & 0.993307149 & 0.83 & \\
\hline 760 & 0.83 & 6 & 0.997527377 & 0.83 & \\
\hline 785 & 0.83 & 7 & 0.999088949 & 0.83 & \\
\hline
\end{tabular}




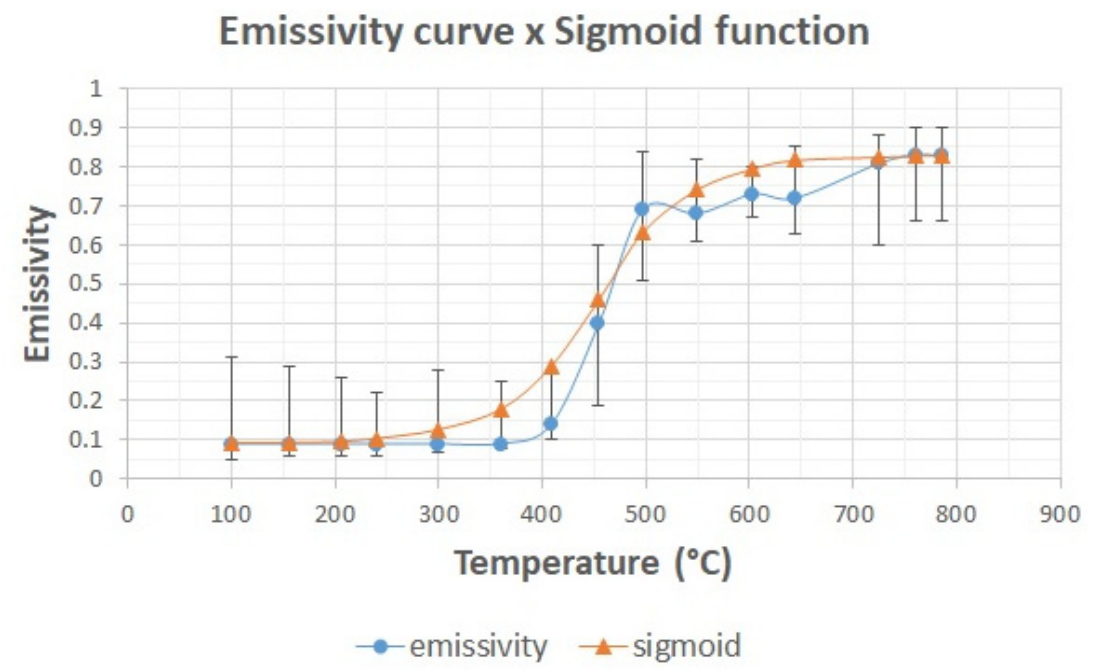

Figure 6. Comparison between the emissivity curve and the optimal sigmoidal function.

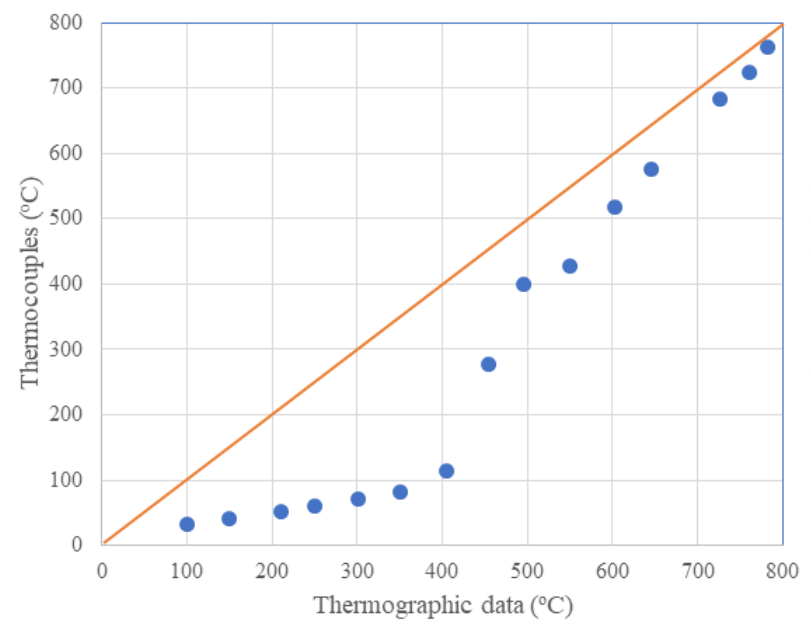

a) Constant reference value for emissivity $(0.95)$

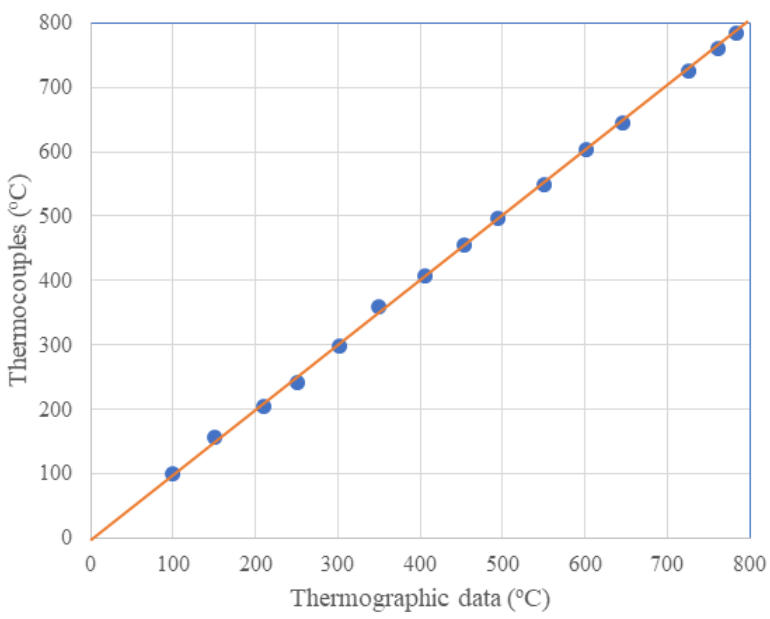

b) Corrected emissivity

Figure 7. Comparison of the thermocouple and thermography data measurements before (a) and after correction method (b)

These comparative results clearly demonstrated the advantages of the use of the sigmoidal curve to adjust the measured data of the thermographic camera during dynamic measurements on-site where the effective emissivity depends on the temperature and surface properties conditions. As can be observed in Figure 7(b), the measured values using the two different methods are very close, after using the dynamic emissivity corrections. The statistics of measurements with errors are presented in Table 5. As can be observed, the general accuracy of the measurement method is very good, although recognizing the complexity of the dynamic measurements carried out. Therefore, we indicated that this methodology is suitable for accurate monitoring of the temperature profiles of the seam welding process during the continuous annealing of low carbon steel at an integrated steel plant of large capacity, as tested during this research.

\subsection{Use of the emissivity curve in the thermographic data correction}

The thermography welds thermal profiles registered with a constant initial emissivity adjustment of 0.27 were submitted to values correction through the methodology developed in this work. Through the interpolation of the 
temperature and emissivity values in the sigmoid function, the convergence between these values in the thermography software and sigmoid function was performed to obtain the thermal profiles corrected by the emissivity curve.

Figure 8 shows the comparison of the three thermal profiles (welding heats inputs: low, medium and high) based on a constant initial emissivity $(\mathrm{e}=0.27)$ with the corrected thermal profiles. It can be observed the displacement of the thermal patterns to the real temperature zone and greater thermal profile stability, through the methodology used for data corrections.
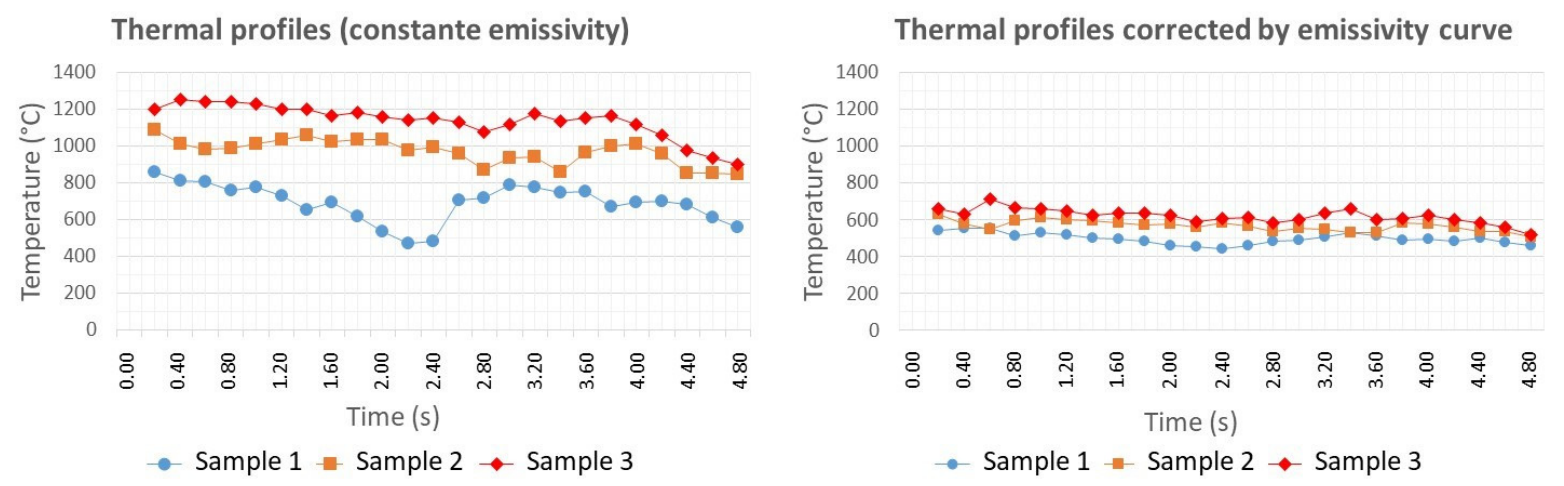

Figure 8. Comparison between the welding thermal profiles before and after the emissivity correction.

The correlation for the emissivity curve incorporated in the thermography software worked within the whole weld's thermal profile range analyzed from $441^{\circ} \mathrm{C}$ to $713^{\circ} \mathrm{C}$, as shown in Figure 8 . The temperature profile after the corrections of the dynamic effective emissivity take place showed uniform and desirable pattern to avoid heterogeneity of the welded regions during the continuous annealing process of the low carbon steel.

\section{Conclusion}

- The use of constant emissivity as a reference value for the acquisition of thermographic data proved to be inaccurate for the analysis and control of continuous welding processes in the environmental conditions of an industrial process. In this study, the sample showed a significant dependence on emissivity as a function of temperature. The average normal sample emissivity ranged from 0.09 to 0.83 at the temperature of $100^{\circ} \mathrm{C}$ to $800^{\circ} \mathrm{C}$;

- The sigmoid function used to correct thermal profiles as a function of emissivity proved to be effective, from which it was possible to perform the convergence between the temperature values recorded via thermography software and the emissivity curve in the studied range of $441^{\circ} \mathrm{C}$ at $713^{\circ} \mathrm{C}$ for the heats inputs used in welding;

- The results showed that the presented methodology could be applied, in a similar way, in the correction of thermal profiles obtained by thermography for other types of welding processes.

\section{Acknowledgments}

The authors thank Universidade Federal Fluminense, CAPES, CNPq, FAPERJ and CSN steel company for the technical and materials support of this research.

\section{References}

Bhadeshia, H. K. D. H., \& Honeycombe, R. W. K. (2006). Steels microstructure and properties. Retrieved from https://www.elsevier.com/books/steels-microstructure-and-properties/bhadeshia/978-0-7506-8084-4

Boillot, J. P., Cielo, P., Begin, G., Michel, C., Lessard, M., Fafard, P., \& Villemure, D. (1985). Adaptive Welding By Fiber Optic Thermographic Sensing: an Analysis of Thermal and Instrumental Considerations. Welding Journal (Miami, Fla), 64(7).

Brioschi M. L. (2011). Metodologia de normalização de análise do campo de temperaturas em imagem infravermelha humana (Unpublished master dissertation). Universidade Federal do Paraná, Curitiba, PR, Brazil.

Broberg, P., Sjödahl, M., \& Runnemalm, A. (2015). Comparison of NDT-methods for automatic inspection of weld defects. International Journal of Materials and Product Technology, 50(1), 1-21. https://doi.org/10.1504/IJMPT.2015.066863 
Chen, J., \& Feng, Z. (2015). IR-based spot weld NDT in automotive applications (S.-J. Hsieh \& J. N. Zalameda, Eds.). Thermosense: Thermal Infrared Applications XXXVII, p. 948513. https://doi.org/10.1117/12.2177124

Darmstadt, P. S., Karlsruhe, V. G., Hamburg, S. K., Karlsruhe, M. K., Karlsruhe, H. M., Hannover, D. M., et al. (2006). VDI - Warmeatlas. Dusseldorf, Deutschland: Verein Deutscher Ingenieuer, VDI - Gesselschaft Verfahrenstechnik und Chemieingenieurwesen.

Demarque, R., de Castro, J. A., Xavier, C. R., da Silva Almeida, D. S., de Jesus Marcelo, C., dos Santos, E. P., \& de Queiroz, A. V. (2017). Numerical and experimental study of the microstructural evolution and the properties of joints welded on rebars using the GMAW process. Welding International, 31(6), 425-434. https://doi.org/10.1080/09507116.2016.1218610

Demarque, R., dos Santos, E. P., Silva, R. S., \& de Castro, J. A. (2018). Evaluation of the effect of the thermal cycle on the characteristics of welded joints through the variation of the heat input of the austhenitic AISI 316L steels by the GMAW process. Science and Technology of Materials, 30, 51-59. https://doi.org/10.1016/j.stmat.2018.09.001

Deus, V. S. de, Castro, J. A., \& Correa, S. R. (2020). Correlation Among the Input Thermal Parameters and Thermography Measurements Data of the Resistance Seam Welding. Materials Research, 23(1). https://doi.org/10.1590/1980-5373-mr-2020-0029

Deus, V. S. de, Corrêa, S. R., \& Castro, J. A. de. (2018). Correlação Do Aporte Térmico Com Os Parâmetros Do Processo De Soldagem Por Costura Aplicada Em Aço Baixo Carbono. ABM Proceedings, pp. 338-348. https://doi.org/10.5151/1516-392x-31346

Kou, S. (2003). Welding Metallurgy. New Jersey: Wiley-Interscience.

Jalaal, M., Ghasemi, E., Ganji, D. D., Bararnia, H., Soleimani, S., Nejad, M. G., \& Esmaeilpour, M. (2011). Effect of temperature-dependency of surface emissivity on heat transfer using the parameterized perturbation method. Thermal Science, 15(1), 123-125. https://doi.org/10.2298/TSCI11S1123J

Novo, M. M. M., Bitencourt, C. S., Tiba, P. R. T., Silva, D. G. M., \& Pandolfelli, V. C. (2014). Fundamentals on emissivity and its correlation with the refractory materials, energy saving and the environment. Ceramica, 60(353), 22-33. https://doi.org/10.1590/S0366-69132014000100004

Palacios, A. M. G. (2010). Uso de técnicas de termografia para deteç̧ão de descontinuidades no processo GTAW através do monitoramento da poça de fusão (Unpublished master dissertation). Universidade de Brasília, Brasilia, DF, Brazil. https://repositorio.unb.br/handle/10482/8622

Paloposki, T., \& Liedquist, L. (2005). Steel emissivity at high temperatures. Finland: VTT Technical Research Centre of Finland, 1-81. (VTT Research Notes). Report No.: 2229. Retrieved from https://www.vttresearch.com/sites/default/files/pdf/tiedotteet/2005/T2299.pdf

Perin, A. L. (2009). Desenvolvimento de um equipamento para medição de emissividade (Unpublished master dissertation). Universidade Federal do Rio Grande do Sul, Porto Alegre, RS, Brazil. Retrieved from https://lume.ufrgs.br/bitstream/handle/10183/15838/000691572.pdf?sequence=1

Richmond, J. C., Harrison, W. N. (1962). Total hemispherical emittance of coated and uncoated inconel and types 321 and 430 stainless steel. Journal of Research of the National Bureau of Standards-C Engineering and Instrumentation, 3, 261-269. https://doi.org/10.1111/j.1151-2916.1959.tb13585.x

Silva, G. C., de Castro, J. A., Filho, R. M. M., Caldeira, L., \& Lagares, M. L. (2019). Comparing two different arc welding processes through the welding energy: a selection analysis based on quality and energy consumption. Journal of the Brazilian Society of Mechanical Sciences and Engineering, 41(7), 301. https://doi.org/10.1007/s40430-019-1804-x

Valiorgue, F., Brosse, A., Naisson, P., Rech, J., Hamdi, H., \& Bergheau, J. M. (2013). Emissivity calibration for temperatures measurement using thermography in the context of machining. Applied Thermal Engineering, 58(1-2), 321-326. https://doi.org/10.1016/j.applthermaleng.2013.03.051

Woo, W., Chin, C. W., Feng, Z., Wang, H., Zhang, W., Xu, H., \& Sklad, P. S. (2009). Application of infrared imaging for quality inspection in resistance spot welds (D. D. Burleigh \& R. B. Dinwiddie, Eds.). Thermosense XXXI, p. 729912. https://doi.org/10.1117/12.818368

Xavier, C. R., Delgado, H. G., \& De Castro, J. A. (2011). Numerical evaluation of the weldability of the low alloy ferritic steels T/P23 and T/P24. Materials Research, 14(1), 73-90. https://doi.org/10.1590/S151614392011005000019 
Xavier, C. R., Delgado, H. G., De Castro, J. A., \& Ferreira, A. F. (2016). Numerical predictions for the thermal history, microstructure and hardness distributions at the HAZ during welding of low alloy steels. Materials Research, 19(3), 520-533. https://doi.org/10.1590/1980-5373-MR-2015-0068

\section{Copyrights}

Copyright for this article is retained by the author(s), with first publication rights granted to the journal.

This is an open-access article distributed under the terms and conditions of the Creative Commons Attribution license (http://creativecommons.org/licenses/by/4.0/). 